\title{
Immune Checkpoint Inhibitors in the Treatment of Renal Cancer: Current State and Future Perspective
}

\author{
Daniele Lavacchi ${ }^{1}$, Elisa Pellegrini ${ }^{1}$, Valeria Emma Palmieri ${ }^{1}$, Laura Doni ${ }^{1}$, \\ Marinella Micol Mela ${ }^{1}$ (D), Fabrizio Di Maida ${ }^{1}$ (D), Amedeo Amedei ${ }^{2}$ (D), Serena Pillozzi ${ }^{1}$, \\ Marco Carini ${ }^{1,2}$ and Lorenzo Antonuzzo ${ }^{1,2, *}$ \\ 1 Clinical Oncology Unit, AOU Careggi, 50134 Firenze, Italy; daniele.lavacchi@yahoo.it (D.L.); \\ pellegrinie81@gmail.com (E.P.); valeriaemmap@gmail.com (V.E.P.); doni.laura@gmail.com (L.D.); \\ micolmela@yahoo.it (M.M.M.); fabridima90@gmail.com (F.D.M.); serena.pillozzi@unifi.it (S.P.); \\ marco.carini@unifi.it (M.C.) \\ 2 Department of Experimental and Clinical Medicine, University of Firenze, 50134 Firenze, Italy; \\ amedeo.amedei@unifi.it \\ * Correspondence: lorenzo.antonuzzo@unifi.it
}

Received: 26 May 2020; Accepted: 25 June 2020; Published: 30 June 2020

\begin{abstract}
Systemic treatment of renal cancer (RCC) has undergone remarkable changes over the past 20 years with the introduction of immunotherapeutic agents targeting programmed cell death (PD-1)/programmed death-ligand 1 (PD-L1) axis, as a single-agent or combined with anti-CTLA-4 monoclonal antibodies (MoAbs) or a multi-target vascular endothelial growth factor-(VEGF) tyrosine kinase inhibitor (TKI). In this paper, we review the main evidence on the use of Immune Checkpoint Inhibitors (ICIs) for RCC treatment from the first demonstration of activity of a nivolumab single agent in a phase I trial to the novel combination strategies (anti-PD-1 plus anti-CTLA4 or anti-PD-1 plus TKI). In addition, we discuss the use of anti-PD-1/PD-L1 agents in patients with non-clear cells and rare histological subtype RCC. Then, we critically examine the current findings in biomarkers that have been proposed to be prognostic or predictive to the response of immunotherapy including immune gene expression signature, B7-H1 expression, PBRM1 loss of function, PD-L1 expression, frame shift indel count, mutations in bromodomain-containing genes in patients with MiT family translocation RCC (tRCC), high expression of the T-effector gene signature, and a high myeloid inflammation gene expression pattern. To date, a single biomarker as a predictor of response has not been established. Since the dynamic behavior of the immune response and the different impact of ICI treatment on patients with specific RCC subtypes, the integration of multiple biomarkers and further validation in clinical trials are needed.
\end{abstract}

Keywords: immune checkpoint inhibitors; renal cell carcinoma; tyrosine kinase inhibitors; predictive biomarkers

\section{Introduction}

Renal cell carcinoma (RCC) is the third urological cancer accounting for approximately $3-5 \%$ of all newly diagnosed tumors [1]. Around 400,000 cases of RCC are diagnosed worldwide every year with $30 \%$ of patients having advanced-stage or metastatic disease at diagnosis with an estimated 5-year survival rate of $10 \%[1,2]$. Among histological subtypes, clear cell (cc) histology is most prevalent, accounting for about $75 \%$ of cases and the other histologies mainly encompass papillary $(20 \%)$ and chromophobe RCC (5\%). The other entities are very rare including translocation-associated RCC, medullar RCC, and collecting duct carcinoma.

Significant changes in the treatment landscape for patients with RCC have been registered over the past 20 years [3]. Traditional immunotherapy involving IFN- $\alpha$ and IL-2 was the main treatment for 
metastatic RCC (mRCC) before the approval of targeted therapies. The efficacy of IFN- $\alpha$ for mRCC patients was first reported in 1989 by Oliver et al. [4] with a response rate of roughly $15 \%$ and with 6 monthes increase in overall survival (OS). According to the Cochrane meta-analysis, IFN- $\alpha$ offers only a small survival improvement when compared to other control regimens. Moreover, responses to IFN- $\alpha$ were not long-lasting and few patients showed complete responses (CRs) [5]. High dose (HD) IL-2 was approved in 1992 for treating mRCC, which offered an objective response rate (ORR) of $10-20 \%$ and a complete remission in $7-10 \%$ of patients. Nearly all patients remained free of disease up to 20 years after therapy [6]. Therefore HD IL-2 had become the preferred treatment for mRCC, but severe toxicity in various organ systems, most significantly the heart, lungs, kidney, and central nervous system, limited its applicability to highly selected patients $[7,8]$. Since the evidence of activity of targeted therapy as the multitarget vascular endothelial growth factor (VEGF) tyrosine kinase inhibitors (TKIs) and mammalian target of rapamycin (mTOR) inhibitors, the treatment of cytokine alone has gradually fallen out of favor.

The treatment options for patients with RCC have been expanding in the last few years [9] after the advent of immunotherapeutic agents targeting programmed death-1 (PD-1)/programmed death-ligand 1 (PD-L1) axis as a single-agent (Table 1) or combined with anti-CTLA-4 monoclonal antibodies (MoAbs) [10]. More recently, the combination of immunotherapeutic agents with antiangiogenic agents has proven to be a promising therapeutic strategy [11].

In this case, we review the main evidence on the use of ICIs for RCC treatment. Then we critically examine the current findings in biomarkers that have been proposed to be predictive of response to immunotherapy. 
Table 1. Summary of the main phase II and III trials of anti-PD-1/PD-L1 MoAb single agent.

\begin{tabular}{|c|c|c|c|c|c|c|c|c|c|c|c|}
\hline Trial & Phase & Treatment Setting & Arms & $\begin{array}{c}\text { Number } \\
\text { of } \\
\text { Patients }\end{array}$ & Risk Groups (\%) & $\begin{array}{c}\text { Previous } \\
\text { Nephrectomy (\%) }\end{array}$ & $\begin{array}{l}\text { Primary } \\
\text { End-Point }\end{array}$ & ORR (\%) & $\begin{array}{l}\text { DCR } \\
(\%)\end{array}$ & PFS (Months) & OS (Months) \\
\hline NCT0135443/ & II & $\begin{array}{l}\text { at least 2nd line in } \\
\text { mRCC with a } \\
\text { clear-cell component } \\
\text { after previous } \\
\text { antiangiogenic } \\
\text { therapy }\end{array}$ & $\begin{array}{c}\text { Nivolumab } 0.3 \\
\mathrm{mg} / \mathrm{kg}, 2 \mathrm{mg} / \mathrm{kg} \text {, or } \\
10 \mathrm{mg} / \mathrm{kg} \mathrm{IV} \mathrm{every} \\
\text { 3 weeks }\end{array}$ & 168 & $\begin{array}{c}\text { MSKCC risk } \\
\text { group: Favorable } \\
33 \% \text {, Intermediate } \\
42 \% \text {, Poor } 25 \%\end{array}$ & $\begin{array}{l}98 \% \text { of patients } \\
\text { received prior } \\
\text { surgery (type of } \\
\text { surgery not } \\
\text { specified) }\end{array}$ & PFS & $\begin{array}{l}20 \%, 22 \% \text {, and } 20 \% \\
\text { in each arm } \\
\text { respectively }\end{array}$ & NR & $\begin{array}{l}2.7,4.0, \text { and } 4.2 \\
\text { months in each } \\
\text { arm respectively }\end{array}$ & $\begin{array}{c}18.2,25.5 \text { and } 24.7 \\
\text { months in each } \\
\text { arm respectively }\end{array}$ \\
\hline $\begin{array}{l}\text { NCT01668784/CheckMate } \\
025\end{array}$ & III & $\begin{array}{l}\text { at least } 2 \text { nd line in } \\
\text { advanced or mRCC } \\
\text { with a clear-cell } \\
\text { component and } \\
\text { previous treatment } \\
\text { with one or two } \\
\text { antiangiogenic } \\
\text { therapies }\end{array}$ & $\begin{array}{c}\text { Nivolumab } 3 \\
\mathrm{mg} / \mathrm{kg} \text { IV every } 2 \\
\text { weeks vs. } \\
\text { everolimus daily } \\
\text { oral dose of } 10 \mathrm{mg}\end{array}$ & 821 & $\begin{array}{c}\text { MSKCC risk } \\
\text { group: Favorable } \\
36 \% \text {, Intermediate } \\
\text { 49\%, Poor 15\% }\end{array}$ & $\begin{array}{l}88 \% \text { of patients } \\
\text { received prior } \\
\text { nephrectomy }\end{array}$ & OS & $\begin{array}{l}25 \% \text { with } \\
\text { nivolumab and } 5 \% \\
\text { with everolimus }\end{array}$ & NR & $\begin{array}{l}4.6 \text { months with } \\
\text { nivolumab and } 4.4 \\
\text { months with } \\
\text { everolimus }\end{array}$ & 25.0 vs. 19.6 \\
\hline NCT03126331/ & II & $\begin{array}{c}\text { mRCC of any } \\
\text { histology (clear cell } \\
93 \% \text {, papillary } 7 \% \text { ) } \\
\text { who received at least } \\
\text { one prior } \\
\text { anti-angiogenic } \\
\text { therapy }\end{array}$ & $\begin{array}{l}\text { Single-arm: } \\
\text { nivolumab for } 12 \\
\text { w ( } 240 \mathrm{mg} \text { every } 2 \\
\text { w or } 480 \mathrm{mg} \text { every } \\
4 \mathrm{w}) \text {, patients with } \\
\geq 10 \% \text { reduction in } \\
\text { tumor burden } \\
\text { entered a } \\
\text { treatment-free } \\
\text { observation phase }\end{array}$ & 14 & $\begin{array}{c}\text { IMDC risk group: } \\
\text { Favorable } 7 \% \text {, } \\
\text { Intermediate } 86 \% \text {, } \\
\text { Poor } 7 \%\end{array}$ & $\begin{array}{l}100 \% \text { of patients } \\
\text { had a prior } \\
\text { nephrectomy }\end{array}$ & $\begin{array}{l}\text { feasibility } \\
\text { of } \\
\text { intermittent } \\
\text { nivolumab } \\
(\geq 80 \% \text { of } \\
\text { patients } \\
\text { eligible } \\
\text { for } \\
\text { intermittent } \\
\text { therapy } \\
\text { elect to } \\
\text { receive } \\
\text { intermittent } \\
\text { nivolumab) }\end{array}$ & t & NR & 7.97 months & NR \\
\hline
\end{tabular}

Abbreviations: MoAb: monoclonal antibody; NR: not reported; $w$ = week. 


\section{Methodology}

We used the PubMed general portal to search for prior reviews that match our study question (immunotherapy, renal carcinoma) and then for original published/unpublished articles (61 full text articles assessed for eligibility). Additionally, we searched on ClinicalTrials.gov for clinical studies.

\section{Anti-PD-1/PD-L1 Single Agent}

The activity of nivolumab was first investigated in a phase I study [12] that evaluated the safety, pharmacokinetics, and efficacy in some solid tumors, including RCC. A maximum tolerated drug dose has not been defined in this study (investigated dose: up to $10 \mathrm{mg}$ per kilogram of body weight every two weeks). Responses were observed in 4 out of 17 (24\%) RCC patients treated with a dose of 1 mg per kilogram and in 5 out of $16(31 \%)$ treated with $10 \mathrm{mg}$ per kilogram. The toxicity profile was acceptable, drug-related grade (G) 3 or 4 adverse events (AE) that occurred in $14 \%$ of patients (Table 2).

Table 2. AEs in the main phase II and III trials of anti-PD-1/PD-L1 MoAb single agents.

\begin{tabular}{|c|c|c|c|}
\hline Trial & G3-4 AEs (\%) & $\begin{array}{l}\text { Most Commonly Reported } \\
\text { G3-4 AEs }\end{array}$ & $\begin{array}{c}\text { Discontinuation Rate Due } \\
\text { to Treatment-Related } \\
\text { AEs (\%) }\end{array}$ \\
\hline NCT01354431/ & $11 \%$ & Transaminases increased & $7 \%$ \\
\hline $\begin{array}{l}\text { NCT01668784/ } \\
\text { CheckMate 025 }\end{array}$ & $\begin{array}{c}19 \% \text { with nivolumab } 37 \% \\
\text { with everolimus }\end{array}$ & $\begin{array}{c}\text { fatigue (3\%), anemia }(2 \%), \\
\text { pneumonitis }(2 \%) \text { with } \\
\text { nivolumab; anemia }(8 \%), \\
\text { hypertriglyceridemia }(5 \%), \\
\text { hyperglycemia }(4 \%), \text { stomatitis } \\
\text { (4\%) with everolimus }\end{array}$ & $\begin{array}{l}8 \% \text { with nivolumab, } 13 \% \\
\text { with everolimus }\end{array}$ \\
\hline
\end{tabular}

Abbreviations: AE: adverse event; G: grade; MoAb: monoclonal antibody.

In a blinded, randomized, multi-center phase II trial, mRCC patients who had received at least one previous anti-angiogenic therapy received nivolumab $0.3 \mathrm{mg} / \mathrm{kg}, 2 \mathrm{mg} / \mathrm{kg}$, or $10 \mathrm{mg} / \mathrm{kg}$ every three weeks [13]. The primary end point was to compare the Progression-Free Survival (PFS) in the three treatment arms to evaluate a possible correlation with the administered dose. Secondary end points were PFS, Objective Response Rate (ORR), time to response, duration of response, Overall Survival (OS) rate, and Adverse Event (AE) rate. The 168 randomized patients were stratified by the Motzer Score For Renal Cell Carcinoma(MSKCC) risk group and number of previous treatments in the metastatic setting. Median PFS was 2.7 months ( $80 \%$ CI, 1.9 months to 3.0 months), 4.0 months $(80 \% \mathrm{CI}$, 2.8 months to 4.2 months), and 4.2 months ( $80 \%$ CI, 2.8 months to 5.5 months) in the $0.3 \mathrm{mg} / \mathrm{kg}, 2 \mathrm{mg} / \mathrm{kg}$, and $10 \mathrm{mg} / \mathrm{kg}$ group, respectively (stratified trend test $p=0.9$ ). ORR was $20 \%, 22 \%$, and $20 \%$ in each arm (exact Cochran-Armitage trend test $p=1.0$ ) and median OS were 18.2 months, 25.5 months, and 24.7 months, respectively. No association between dose and response was observed. Treatment-related AEs were predominantly low grade with G3-4 AEs in $11 \%$ of cases. No high-grade pneumonitis was observed. In an exploratory analysis, median PFS was 4.9 months in the PD-L1 $\geq 5 \%$ subgroup and 2.9 months in the PD-L1 < 5\% subgroup.

A randomized, multi-center, open-label, phase III trial, Checkmate 025, investigated the effectiveness of nivolumab vs. everolimus (mTOR inhibitor) [14]. The study population included mRCC patients with a clear-cell component previously treated with one or two anti-angiogenics. The primary end point was OS, which was significantly longer in the nivolumab arm ( 25 months) than in the everolimus arm (19.6 months). Secondary end points included ORR and safety. The nivolumab advantage (compared with everolimus) was also evident in secondary end points with an ORR of $25 \%$ vs. $5 \%(p<0.001)$ and a better safety profile. In particular, G3 or G4 treatment-related AEs occurred in $19 \%$ and $37 \%$ of patients in the nivolumab arm and in the everolimus arm, respectively. Most commonly reported AEs were fatigue (3\%) with nivolumab and anemia $(8 \%)$ with everolimus. Median PFS were 4.6 and 4.4 months, respectively $(p=0.11)$. In a post-hoc analysis of patients who had not progressed 
or died at 6 months, median PFS was 15.6 months in the nivolumab group and 11.7 months in the everolimus group. The expression of PD-L1 was not associated with response to nivolumab. Assuming $1 \%$ and $5 \%$ as cut-off, a correlation between PD-L1 expression and poor prognosis was reported (likely due to the type of tumor and histology). An update has been recently presented after more than 5 years of follow-up [15]. ORR ( $23 \%$ with nivolumab vs. $4 \%$ with everolimus) and OS ( 25.8 months vs. 19.7 months) remained superior with nivolumab and $28 \%$ of responses to nivolumab were ongoing, while, with everolimus, ongoing responses were observed in $18 \%$ of patients. Furthermore, in the nivolumab group, median duration of the response (DOR) was longer (18.2 months vs. 14.0 months) than in the everolimus group.

A phase II trial explored the use of intermittent nivolumab in mRCC patients that had received prior anti-angiogenic therapy [16]. Patients were treated with nivolumab for 12 weeks and those who achieved $\geq 10 \%$ reduction in the tumor burden initiated a treatment-free observation phase. The primary objective was feasibility of intermittent nivolumab, as the percentage of patients eligible for intermittent therapy who have accepted this treatment scheme (assumed as "feasible" if the acceptance rate was $\geq 80 \%$ ). A total of 14 patients were enrolled and 5 patients accepted intermittent nivolumab treatment. With a median follow-up of 48 weeks, only one patient needed to restart therapy while the others kept their response for a median of 34 (range, 16-53) weeks off therapy. It was a small-sized study, which brings out the following concepts: in the era of combination therapies, identifying clear responder patients to immunotherapy who could benefit from a suspension, may have an important task in terms of reducing toxicity and costs.

A phase II study investigated the switch to nivolumab vs. TKI continuation after 12 weeks of TKI induction therapy [17]. This trial was prematurely closed because of low accrual rate. It included patients who had an advanced or metastatic clear cell RCC with partial response (PR) or stable disease (SD) to induction therapy with sunitinib or pazopanib. Patients were randomized to TKI continuation or switched to nivolumab ( $240 \mathrm{mg}$ intravenously [IV] every two weeks or $480 \mathrm{mg}$ IV every four weeks). Stratification factors were MSKCC risk, previous TKI, and response to TKI. In a further interim analysis, ORR was $64 \%$ in the nivolumab group vs. $70 \%$ in the TKI group when assessed from the start of induction therapy ( $p=0.76$ ) and $16 \%$ vs. $48 \%$, respectively, when assessed from the time of randomization $(p=0.032)$. PFS from randomization was 3.0 months for nivolumab and 11.9 months for TKI ( $p=0.0026)$. At a median follow-up of 12.9 months, median OS was not reached. The continuation of TKI in patients sensitive to these drugs appeared to be more effective than the switch to nivolumab. However, the small sample size and the early study termination may have limited the strength of the results. In the last few years, single-agent ICIs seem to be promising in the perioperative setting and may change the usual clinical practice.

A randomized, unblinded phase III trial comparing perioperative nivolumab vs. observation in RCC patients undergoing nephrectomy is ongoing [18]. The rationale for this study was to prime the immune system before nephrectomy by taking into account the feasibility of immunotherapy single-agent and its good safety profile that does not delay surgery. Patients with clinical stage $\geq \mathrm{T} 2 \mathrm{~N} \times \mathrm{M} 0$ or TanyN $+\mathrm{M} 0$ or oligometastatic ( $\leq 3$ sites of metastases that can be radically resected) are randomized to receive nivolumab $480 \mathrm{mg}$ every four weeks of the schedule for only one neoadjuvant administration before nephrectomy, which is followed by nine adjuvant cycles vs. observation. The primary end point is recurrence-free survival (RFS). The study strength is the opportunity to analyze tissue before and after exposure to immunotherapy and, consequently, to study potential markers.

Another ongoing study (phase II single center) is evaluating nivolumab in the perioperative setting in metastatic patients who plan to undergo cytoreductive nephrectomy [19]. Nivolumab is administered at a dose of $3 \mathrm{mg} / \mathrm{kg}$ every 2 weeks for eight weeks pre-cytoreductive nephrectomy and post-operatively until undergoing progressive disease (PD). The primary end point is represented by safety while secondary end points are represented by a response evaluation and an exploratory biomarker analysis. At median follow-up of 12.5 months, an acceptable toxicity profile was registered. 
The baseline immune gene expression pattern was different between responders and non-responders. In particular, the presence of tumor infiltrating lymphocytes was associated with lasting responses.

Another ICI, pembrolizumab, has been studied in a single-arm, open-label, phase II study as first-line treatment in patients with RCC. This study had two cohorts: patients with advanced clear cell RCC and non-clear cell RCC (nccRCC). The primary end point was ORR. Results of cohort A were presented at a median follow-up of 23 months. The ORR was $36.4 \%$ with a CR of $2.7 \%$, a time to respond of 2.8 months, and a median duration of response was not reached. Median PFS was 7.1 months and the median OS was unreached. Moreover, considering a combined positive score (CPS), ORR in patients with CPS $\geq 1$ was $44.2 \%$, and in patients with CPS $<1$ was $29.3 \%$ [20].

Results of cohort B were presented at a median follow-up of 15 months. The predominant histology was papillary $(72 \%)$, which was followed by the chromophobe $(13 \%)$ and unclassified $(16 \%)$. Moreover, $62 \%$ were PD-L1+. In RC patients with the non-clear cell variant, the ORR was $26.1 \%$ while the median duration of response was 15.3 months. In particular, ORR was $28.0 \%$ in papillary, $9.5 \%$ in chromophobe, and $30.8 \%$ in unclassified nccRCC. ORR in patients with CPS $\geq 1$ was $35.3 \%$ and in patients with CPS $<1$ was $10.3 \%$ [21].

Pembrolizumab has been studied in the adjuvant setting. A randomized, double-blind, placebo-controlled, phase III study is underway (KEYNOTE-564 trial) [22]. The primary end point is disease free survival (DFS) per the investigator assessment and the secondary end point is OS. Randomization will be stratified by the metastasis stage (M0 vs. M1).

In the same setting, another study evaluating the activity of atezolizumab is ongoing [23]. RCC patients who have undergone nephrectomy and are at high risk of recurrence (T2 grade 4, T3a grade $3-4, \mathrm{~T} 3 \mathrm{~b} / \mathrm{c}$ any grade, $\mathrm{T} 4$ any grade, or $\mathrm{T} \times \mathrm{N}+$ any grade) or have had complete resection of limited metachronous/synchronous metastasis will be randomized to receive atezolizumab $1200 \mathrm{mg}$ IV every three weeks or placebo IV every three weeks for 16 cycles or one year. Stratification factors are disease stage, geographic region, and PD-L1 status on tumor-infiltrating immune cells. The primary end point is independent of review facility-assessed DFS.

Avelumab, another ICI, has also been shown to be effective as monotherapy in first and second line treatment, according to phase $1 \mathrm{~b}$ results from the Javelin Solid Tumor Trial, in which Disease Control Rate DCR was similar in both groups (77.4\% in the first line, $75.0 \%$ in the second line) and a 12-month OS rates was $83.7 \%$ and $65.0 \%$, respectively, in the first and second line [24].

\section{Anti-PD-1/PD-L1 Combined with Other Agents}

The combination of two ICIs has been recently tested in patients with RCC. Motzer and colleagues [25] recently reported results of CheckMate 214, which is a phase III trial that demonstrated the superiority of the combination of ipilimumab and nivolumab over sunitinib in previously untreated patients with intermediate/poor risk (according to International Metastatic RCC Database Consortium [IMDC] prognostic model) metastatic or locally advanced clear cell RCC (Table 3). This open-label multi-center trial randomized nivolumab $(3 \mathrm{mg} / \mathrm{kg})+$ ipilimumab $(1 \mathrm{mg} / \mathrm{kg})$ every two weeks vs. sunitinib (50 mg daily) orally once daily for 4 weeks (6-week cycle) as first-line treatment in patients with metastatic clear cell RCC. The coprimary end points were OS, ORR, and PFS. A total of 1096 patients were assigned to receive nivolumab plus ipilimumab (550 patients) or sunitinib (546 patients). Overall, 425 had intermediate risk and 422 had poor risk. At a median follow-up of 25.2 months, the 18-month OS in the intermediate and poor-risk patients was 75\% with nivolumab + ipilimumab and it was $60 \%$ with sunitinib. The median OS was not reached with the combination therapy vs. 26.0 months with sunitinib (HR, $0.63, p<0.001)$. ORR was also superior in the ICI group than in the sunitinib group ( $42 \%$ vs. $27 \%$, respectively, $p<0.001$ ) and the CR rate was $9 \%$ in the combination immunotherapy arm vs. $1 \%$ in the sunitinib arm. DCR was similar in the two arms including $72 \%$ in the combination group vs. $71 \%$ in the control group. PFS was 11.6 months vs. 8.4 months, respectively. With extended follow-up [26] (median follow-up 32.4 months (IQR 13.4-36.3)), results for the three co-primary end points showed that nivolumab plus ipilimumab continued to be superior to sunitinib in terms of 
OS (median not reached [95\% CI 35.6-not estimable] vs. 26.6 months (22.1-33.4). HR 0.66 (95\% CI 0.54-0.80), $p<0.0001$ ), PFS (median 8.2 months (95\% CI 6.9-10.0) vs. 8.3 months (7.0-8.8), HR 0.77 (95\% CI 0.65-0.90), $p=0.0014)$, and the ORR (178 (42\%)of 425 vs. 124 (29\%) of $422, p=0.0001)$. PD-L1 status was not predictive of response to the combination therapy. Treatment-related AEs occurred in $93 \%$ of patients in the combination group and 97\% in the control group. G3 or G4 AEs occurred in $46 \%$ and $63 \%$ of patients, respectively (Table 4). Treatment-related AEs leading to discontinuation occurred in $22 \%$ and $12 \%$, respectively. The most commonly reported G3 or G4 AEs in the combination group were elevated lipase levels, fatigue, and diarrhea, while, in the control group, were hypertension, fatigue, palmar-plantar erythrodysesthesia, and elevated lipase levels. There were eight treatment-related deaths in the combination group and four in the sunitinib group.

KEYNOTE-426 was an open-label phase 3 trial that randomized 861 patients with previously untreated metastatic clear cell RCC to receive pembrolizumab (200 mg) IV once every 3 weeks plus axitinib (5 mg) orally twice daily (432 patients) or sunitinib (50 mg) orally once daily for the first 4 weeks of each 6-week cycle (429 patients) [27]. Primary end points were OS and PFS in the intention-to-treat (ITT) population, while secondary end point was ORR. Rationale for choosing axitinib was the best toxicity profile in association with pembrolizumab due to greater selectivity in inhibiting VEGF receptor (VEGFR). Median OS was not reached, but, after a median follow-up of 12.8 months, the estimated percentage of patients who were alive at 12 months was $89.9 \%$ vs. $78.3 \%$ (HR 0.53, 95\% CI, 0.38 to $0.74, p<0.0001)$. The risk of death was $47 \%$ lower with combination therapy when compared to sunitinib. Median PFS was significantly longer with the combination therapy than with sunitinib (15.1 vs. 11.1 months HR $0.69,95 \%$ CI, 0.57 to $0.84, p<0.001$ ). OS and PFS benefit were independent of IMDC risk groups and PDL1 status. The ORR was higher in the combination group than in the control group [59.3\% (95\% CI, 54.5 to 63.9) vs. $35.7 \%(95 \%$ CI, 31.1 to 40.4$), p<0.001$ ]. G3 or G4 AEs of any cause occurred in $75.8 \%$ of patients in the combination group and in $70.6 \%$ in the control group. In the combination group, AEs of any cause led to discontinuation of either drugs in $30.5 \%$ of patients, discontinuation of both drugs in $10.7 \%$, interruption of either drug in $69.9 \%$, and dose axitinib reduction in $20.3 \%$. In the sunitinib group, AEs led to discontinuation in $13.9 \%$ of patients, interruption in $49.9 \%$, and dose reduction in 30.1\%. The most commonly reported G3 or G4 treatment-related AEs in both groups were diarrhea and hypertension. The incidence of hepatic toxicity was higher in the pembrolizumab-axitinib group. However, there were no deaths related to hepatoxicity. There were four treatment-related deaths in the combination group and seven treatment-related deaths in the sunitinib group. It emerged that Pembrolizumab + Axitinib provides benefits in the combined population of patients with IMDC intermediate or poor risk and in patients whose tumors had sarcomatoid features. The observed benefits were consistent with those seen in the total population. In 2019, Rini et al. presented the analysis of intermediate and poor-risk groups in addition to the sarcomatoid group [28]. 105 patients with sarcomatoid features were examined and results showed improvement in OS (HR 0.58, 95\% CI 0.21-1.59, 12-mo rate 83.4\% vs. 79.5\%), PFS (HR 0.54, 95\% CI 0.29-1.00, median not reached vs. 8.4 months), and ORR (58.8\% (95\% CI 44.2-72.4) vs. 31.5\% (19.5-45.6)). Additionally, CR rates were $11.8 \%$ (95\% CI 4.4-23.9) vs. $0 \%$ (0.0-6.6), respectively. 
Table 3. Summary of the main phase II and III trials of anti-PD-1/PD-L1 MoAbs in combination with other agents.

\begin{tabular}{cccccccccc}
\hline Trial & Phase & $\begin{array}{c}\text { Treatment } \\
\text { Setting }\end{array}$ & Arms & $\begin{array}{c}\text { Number of } \\
\text { Patients }\end{array}$ & $\begin{array}{c}\text { Previous } \\
\text { Nephrectomy } \\
(\%)\end{array}$ & $\begin{array}{c}\text { Primary } \\
\text { End-Points }\end{array}$ & ORR (\%) & DCR(\%) & PFS (Months) \\
(Months)
\end{tabular}

Abbreviations: MoAb: monoclonal antibody; NR: not reported.

Table 4. AEs in the main phase II and III trials of anti-PD-1/PD-L1 MoAb in combination with other agents.

\begin{tabular}{|c|c|c|c|}
\hline Trial & G3-4 AEs (\%) & Most Commonly Reported G3-4 AEs & $\begin{array}{l}\text { Discontinuation Rate Due to } \\
\text { Treatment-Related AEs (\%) }\end{array}$ \\
\hline Checkmate 214 & 43 vs. 63 & $\begin{array}{l}\text { - increased lipase level, fatigue diarrhea } \\
\text { - hypertension, palmar-plantar erythrodysesthesia, } \\
\text { fatigue, increased lipase level }\end{array}$ & 22 vs. 12 \\
\hline KEYNOTE-426 & 75.8 vs. 70.6 & $\begin{array}{l}\text { - Diarrhea, hypertension and hepatic toxicity } \\
\text { - Diarrhea, hypertension }\end{array}$ & $\begin{array}{l}\text { both drugs: } 30.5 \text {, } \\
\text { sunitinib: } 13.9\end{array}$ \\
\hline JAVELIN Renal 101 & 71.2 vs. 71.5 & $\begin{array}{l}\text { - hypertension, diarrhea, increased alanine } \\
\text { aminotransferase level, palmar-plantar } \\
\text { erythrodysesthesia } \\
\text { - hypertension, palmar-plantar erythrodysesthesia, } \\
\text { hematological toxicity }\end{array}$ & 7.6 vs. 13.4 \\
\hline IMmotion151 & 40 vs. 54 & $\begin{array}{c}\text { - hypertension, } \\
\text { - hypertension, thrombocytopenia, palmar-plantar } \\
\text { erythrodysesthesia }\end{array}$ & 5 vs. 8 \\
\hline
\end{tabular}

Abbreviations: AE: adverse event; G: grade; MoAb: monoclonal antibody. 
JAVELIN Renal 101 was a randomized (1:1) phase 3 trial, which evaluated the efficacy of avelumab (10 mg/kg, IV every 2 weeks) plus axitinib (5 mg orally twice daily) or sunitinib (50 mg orally once daily for 4 weeks, in 6-week cycle) in 886 patients with previously untreated advanced RCC patients. OS and PFS in patients with PD-L1-positive tumors were the two independent primary end points. PFS in the overall population, ORR, and safety were secondary end points. A total of 560 (63.2\%) patients had a PD-L1-positive tumor. Among these patients, median PFS was 13.8 months in the combination therapy group and 7.2 months in the sunitinib group (HR $0.61,95 \% \mathrm{CI}, 0.47$ to $0.79, p<0.001$ ) in the overall population. Median PFS was 13.8 and 8.4 months, respectively (HR 0.69, 95\% CI, 0.56 to 0.84 , $p<0.001$ ). Among patients with PD-L1-positive tumors, ORR was $55.2 \%$ inavelumab plus axitinib group vs. $25.5 \%$ in the control group. At the time of the analysis, OS data were immature. G3 or higher AEs were observed in $71.2 \%$ and $71.5 \%$ of patients, respectively. The most commonly reported G3 or G4 treatment-related AEs were hypertension, diarrhea, increased alanine aminotransferase level, and palmar-plantar erythrodysesthesia in the combination arm, and hypertension, palmar-plantar erythrodysesthesia, and hematological toxicity in the sunitinib arm with three and one treatment-related deaths, respectively [29].

IMmotion151 was a multi-centre, open-label, phase 3, randomized (1:1) controlled trial evaluating the efficacy of atezolizumab $(1200 \mathrm{mg})$ plus bevacizumab $(15 \mathrm{mg} / \mathrm{kg}) \mathrm{IV}$ every 3 weeks or sunitinib (50 mg orally once daily for 4 weeks on, 2 weeks off) as first-line therapy of advanced RCC in patients with a component of clear cell or sarcomatoid histology [30]. Co-primary end points were investigator-assessed PFS in the PD-L1-positive population and OS in the ITT population. Secondary end points were OS in the PD-L1-positive population, PFS in the ITT population, ORR, duration of response, patient-reported outcomes, and safety. A total of 915 patients were enrolled including $40 \%$ of whom had PD-L1-positive tumors. Among patients with PD-L1-positive tumors, the median PFS was 11.2 months in the combination arm vs. 7.7 months in the control arm (HR $0.7495 \%$ CI 0.57-0.96, $p=0.0217)$. OS was immature at the time of interim analysis. Overall, $40 \%$ of patients in the combination arm and 54\% in the sunitinib arm had treatment-related G3-G4 AEs with discontinuation rated at 5\% and $8 \%$, respectively. The most commonly reported G3-G4 treatment-related AE in the combination arm was hypertension, while, in the sunitinib group, were hypertension, thrombocytopenia, and palmar-plantar erythrodysaesthesia. There were five treatment-related deaths in the combination group and one treatment-related death in the sunitinib group.

\section{Anti-PD1/PD-L1 in Non-Clear Cell RCC (nccRCC) and Rare Histological Subtype}

Despite the favourable results obtained in terms of improvement in OS from ICI therapy in patients with ccRCC, the efficacy of anti-PD-1/PD-L1 agents in patients with ncc- and rare histological subtype-RCC is still debated. These patient populations are often underrepresented or excluded from clinical trials. Therefore, the relatively small size of those who received ICI therapies precludes a precise estimate of the real benefit provided by anti-PD-1/PD-L1 agents in these subgroups.

In a retrospective case series of non-clear cell RCC (nccRCC) patients, $82 \%$ of whom received at least one previous systemic treatment, nivolumab demonstrated an encouraging clinical activity. In particular, DCR was 49\%, ORR was 20\%, and median PFS was 3.5 months [31]. Similarly, in another retrospective cohort of patients treated with anti-PD-1/PD-L1 agents for a ncc RCC, ORR was 19\% and DCR was $52 \%$ with median time-to-treatment failure of 4.0 and OS of 12.9 months [32]. In a single-institution experience, 40 patients with metastatic nccRCC received nivolumab as secondary or further line of treatment. ORR and DCR were $20.6 \%$ and $70.5 \%$, respectively. Three patients $(8.8 \%)$ obtained a CR. Median PFS and OS were 4.9 months and 21.7 months, respectively [20]. Consistent with these results, a phase II trial including previously untreated patients with nccRCC showed a remarkable activity of pembrolizumab. In this study, $24.8 \%$ of patients had a PR or a CR, $81.5 \%$ of whom had a duration of response greater than 6 months. Overall, the rates of PFS and OS at 12 months were $22.8 \%$ and $72.0 \%$, respectively [33]. Updated results at a median follow-up of 15 months showed, among patients with the non-clear cell variant, an ORR of $26.1 \%$ for the whole cohort and median 
duration of response of 15.3 months. The predominant histology was papillary (72\%) with an ORR of $28 \%$, which was followed by a chromophobe (13\%) with an ORR of $9.5 \%$, and unclassified $(16 \%)$ with an ORR of $30.8 \%$.

Additionally, nivolumab and atezolizumab plus bevacizumab have demonstrated a clinical activity in nccRCC. The initial results from the phase IIIb/IV trial CheckMate 374 showed an ORR of $13.6 \%$ and a median OS of 16.3 months. In a phase II trial, the combination of atezolizumab and bevacizumab showed an ORR of 31\% and a DCR of 75\% [34]. In these studies, patients with unclassified, sarcomatoid or rhabdoid differentiation RCC showed a higher rate of response compared with those observed in patients with chromophobe RCC [35].

More recently, the combination therapy of durvalumab and savolitinib (MET inhibitor) in metastatic papillary renal cancer demonstrated clinical activity with a ORR of $27 \%$ and a median OS of 12.3 months [36].

Accounting for $1-4 \%$ of all adult RCCs and $20-40 \%$ of all pediatric RCCs, Xp11 translocation RCC (tRCC) was described as a distinct RCC subtype in the 2004 World Health Organization (WHO) classification, and then it was confirmed as a distinct RCC subtype (i.e., MiT family tRCC) that also includes $t(6 ; 11)$ RCC [37]. The MiT family tRCC harbors the pathognomonic rearrangement of one of the MiT transcription factors TFE3 and TFEB. The prognosis of patients affected by metastatic MiT family tRCC is often poor, since the disease is usually highly aggressive. A retrospective study evaluated the efficacy of ICI therapy in 24 patients with metastatic tRCC. Only one patient received ICI as first-line treatment, while the remaining 23 patients received it as secondary or a further line of treatment. Overall, ORR and DCR were $16.6 \%$ and $29.1 \%$, respectively, with median PFS (range, $1-40$ months) of $2.5 \%$. Four patients experienced partial response $(16.7 \%)$ and three patients $(12.5 \%)$ had stable disease. Despite the limitation of a small number of patients, the study showed objective response in tRCC similar to those observed in ccRCC [38].

\section{Prognostic and Predictive Biomarkers}

ICIs targeting the PD-1/PD-L1 axis have shown durable responses and clinically meaningful activity in RCC patients. Unfortunately, thus far, there are no reliable biomarkers able to predict the efficacy of immunotherapy and define specific subgroups of patients who best respond to anti-PD-1 agents (Table 5). 
Table 5. Summary of the main prognostic and predictive biomarkers for immunotherapy in RCC.

\begin{tabular}{|c|c|c|}
\hline Biomarker & Clinical Significance & References \\
\hline Immune gene expression signature & Better PFS among patients treated with axitinib plus avelumab & [39] \\
\hline B7-H1 expression & Negative prognostic factor for 5-year PFS and 5-year cancer-specific survival rate: & [40] \\
\hline PBRM1 loss of function & $\begin{array}{l}\text { Better clinical benefit among patients who received nivolumab with or without ipilimumab. } \\
\text { Higher ORR, clinical benefit rate, longer PFS, and OS among patients treated with nivolumab. }\end{array}$ & {$[41,42]$} \\
\hline PD-L1 expression & $\begin{array}{l}\text { Negative prognostic factor. } \\
\text { CheckMate } 025 \text { trial: median OS was } 21.8 \text { months in patients whose tumors were PD-L1-positive compared with } 27.4 \text { months in those } \\
\text { whose tumors were PD-L1-negative. However the benefit offered by nivolumab was observed regardless of PD-L1 expression. } \\
\text { CheckMate } 214 \text { trial: PD-L1 expression had a negative prognostic impact on survival for patients treated with sunitinib but not for those } \\
\text { treated with nivolumab plus ipilimumab. }\end{array}$ & {$[13,25]$} \\
\hline Frameshift indel count & Positive predictive factor in patients treated with anti-PD-1 agents. & [43] \\
\hline High expression of T-effector gene signature & Better PFS and ORR among patients treated with atezolizumab plus bevacizumab. & [44] \\
\hline High myeloid inflammation gene expression pattern & Negative prognostic factor for PFS in patients treated with atezolizumab single-agent or atezolizumab combined with bevacizumab & [44] \\
\hline Mutations in bromodomain-containing genes & Long-lasting clinical benefit in two patients with tRCC treated with ICIs. & [38] \\
\hline
\end{tabular}

Abbreviations: ICI: immune checkpoint inhibitor; ORR: overall response rate; OS: overall survival; PD-L1: programmed death-ligand 1; PD-1: Programmed cell death-1; PFS: progression-free survival; tRCC: translocation renal cell carcinoma. 
To date, PD-L1 expression is the most studied predictive biomarkers for the outcome of ICI therapy in several cancer types. However, a comprehensive stratification of patient outcomes cannot be predicted using PD-L1 expression due to limited sensitivity, specificity, reproducibility, and poor reliability of the staining. First, PD-L1 expression is highly heterogeneous both within the tissue specimen and between primary tumor and metastatic sites. Second, PD-L1 expression has been reported to be dynamic and deeply influenced by treatments $[45,46]$. Furthermore, the evaluation of PD-L1 expression is highly dependent on the Ab used. Since different diagnostic antibodies with different staining platforms and scoring systems were used for each anti-PD-1/PD-L1 agent, the reproducibility of immunohistochemical PD-L1 testing is severely limited and sensitivity of each assay cannot be compared to the others [47].

Although the survival benefit associated with ICI therapy was observed across all subgroups of the PD-L1 tumor proportion score (TPS), including PD-L1-negative patients, several studies tried to explore the predictive and prognostic role of PD-L1 in RCC. Baseline PD-L1 expression has been initially associated with poor prognosis in this patient population and data from CheckMate 025 confirmed this correlation, showing a shorter OS in patients with high PD-L1 expression, regardless of what treatment they received (nivolumab or everolimus).

Although the benefit with nivolumab was observed regardless of PD-L1 expression, among patients treated with nivolumab, median OS was 21.8 months in the PD-L1-positive group when compared with 27.4 months in the PD-L1-negative group [13]. In CheckMate 214 trial, PD-L1 expression has a negative prognostic impact on survival for patients treated with sunitinib but not for those treated with the combination therapy. Nivolumab plus ipilimumab, as the first-line therapy, increased OS and ORR when compared to sunitinib in intermediate-risk and poor-risk patients across all the PD-L1 expression levels, but the difference in benefit was higher in patients with PD-L1-positive tumors than in those with PD-L1-negative tumors. In contrast, PFS benefit was significantly different in patients with a PD-L1-positive tumor but not in those with PD-L1-negative tumors [26]. The analysis of biomarkers from JAVELIN Renal 101 trial showed that PFS is significantly shorter in patients with PD-L1-positive tumors when compared with those who had PD-L1-negative tumors in the sunitinib group. In contrast, no difference in PFS was observed in the axitinib plus avelumab group, according to PD-L1 expression. High-angiogenetic expression signature was significantly associated with better PFS in the sunitinib group, but not in the combination arm. Conversely, PFS was significantly longer in patients treated with axitinib plus avelumab whose tumors were positive for an immune gene expression signature [39]. The negative prognostic effect of PD-L1 expression was initially attributed to its immunosuppressive action. Evidence suggested that T-cell co-stimulation might be implicated in the prognosis of RCC patients. Analyzing B7-H1 expression by immunohistochemistry in patients with RCC who had radical nephrectomy and correlating the results with the survival outcomes, a reduction in the risk of progression and death emerged in B7-H1-negative patients when compared to B7-H1-positive patients. B7-H1 is a co-stimulating glycoprotein in the B7 family that is aberrantly expressed by RCC cells and has been implicated in impairment of $\mathrm{T}$ cell function and survival, which resulted in defective host anti-tumoral immunity. In particular, 5-year cancer-specific survival rates were $41.9 \%$ in B7-H1-positive patients and $82.9 \%$ in B7-H1-negative patients [40]. Moreover, the immunomodulatory role of nivolumab was explored in a hypothesis-generating prospective study in which biomarkers were longitudinally monitored during treatment with nivolumab in a population of mRCC patients. Changes in tumor-associated lymphocytes (e.g., CD3+, CD4+, and CD8+), upregulation of INF-gamma stimulated genes in tumor transcripts, and increase in chemokines (e.g., CXCL9 and CXCL10) were observed, while no significant change in PD-L1 expression under nivolumab treatment was reported [48].

In addition, performing a whole exome sequencing from paired tumor/normal tissue in a cohort of RCC patients who received nivolumab with or without ipilimumab, Miao and colleagues showed an association between PBRM1 loss and survival benefit [41]. Accordingly, PBRM1 loss was identified as a biomarker of response to ICI treatment in an independent cohort of patients from a randomized clinical 
trial. Patients whose tumors had PBMR1 loss were more likely to obtain a response from nivolumab treatment. Among patients treated with nivolumab, PBRM1 loss was associated with higher ORR, clinical benefit rate, longer PFS, and longer OS. Conversely, among patients treated with everolimus, PFS, OS, and ORR were not different according to the PBRM1 status [42].

Tumor mutational burden (TMB) has been recently proposed as a predictive biomarker of response to ICIs in patients with different cancer types. However, RCC has been shown to have a low mutational load with a median number of non-silent mutations per mega base 10-400 times lower than melanoma or NSCLC [49-51]. Despite the low TMB, a high absolute number of indels and an impressive proportion of indels out of total mutations characterize RCC. Indel mutations have been described as the main mechanism responsible for the production of neoantigens to which T-cell responses are directed. Being significantly associated with response to PD-1 agents in melanoma, the high burden of indel mutations seems to be a promising biomarker to predict efficacy of immunotherapy, but the evidence remains controversial [52]. This association was confirmed in a cohort of RCC patients treated with anti-PD-1 agents. Despite the limited sample size, the frameshift indel count, but not the mutational burden, was significantly associated with OS. In contrast, among patients treated with TKI, OS was not statistically different [43].

Recently reported data showing a better clinical response to pembrolizumab (anti-PD-1) in MMR-deficient patients support the hypothesis that MMR-deficient tumors respond better to anti-PD-1 therapy than do MMR-proficient tumors [44].

Data from an exploratory analysis of IMmotion151 trial showed significant improvement in PFS and ORR for patients who received atezolizumab plus bevacizumab whose tumor had a high expression of the T-effector gene signature when compared to those with a low expression [30]. However, neither the T-effector gene signature nor the clinical benefit was associated with TMB, tumor neoantigen burden, indel count, or frameshift mutation burden.

The high myeloid inflammation gene expression pattern has been supposed to be another biomarker of response to ICI since it was associated with lower PFS in the atezolizumab single-agent group and atezolizumab combined with bevacizumab group, but not in the sunitinib group [44].

Additionally, in nccRCC, PD-L1 expression resulted in being a predictive biomarker of poor survival and was associated with more aggressive clinical features such as advanced stage and high grade. According to a retrospective study conducted by Choueiri and colleagues [53], PD-L1 had a wide range of expression among specimens of non-clear RCC. Albeit, the study was limited in sample size. The prevalence of PD-L1 expression in tumor cells was $5 \%$ in chromophobe RCC, $10 \%$ in papillary RCC, $30 \%$ in tRCC, and 20\% in collecting duct carcinoma. Analyzing the PD-L1 expression in tumor-infiltrating mononuclear cells, nccRCC showed a marked expression with a prevalence of $36 \%$ in chromophobe RCC, $60 \%$ in papillary RCC, $90 \%$ in Xp11.2 translocation RCC, and $100 \%$ in collecting duct carcinoma. Time to recurrence was significantly affected by PD-L1 expression on tumor cells and tumor-infiltrating cells. In particular, patients with PD-L1 expressed in both tumors and tumor-infiltrating cells had a shorter time to recurrence ( $p=0.02$ and $p=0.03$, respectively) [53].

The molecular characterization could identify additional predictive immunological biomarkers. In a subset of eight patients affected by metastatic MiT family tRCC treated with ICI, the tumor genome was assessed with whole exome sequencing in 4 and targeted sequencing in 4 . The median mutational load was lower than that observed in clear-cell RCCs in The Cancer Genome Atlas (TCGA) project [51]. Additionally, mutations in bromodomain-containing genes (PBRM1 and BRD8) were observed in two patients with a long-lasting control of the disease [38].

\section{Current Treatment Strategies and Perspectives}

The favorable results from phase III trials make ICIs combined with anti-CTLA-4 MoAbs or anti-angiogenic agents the preferred first-line of treatment for the majority of patients with RCC. Unfortunately, the clinical trials responsible for the approval of these novel combination strategies have some limitations due to missing information on randomization, unclear interpretation of PD-L1 
expression, heterogeneous populations, and absence of study data in data analyses. All these aspects make it difficult to obtain a precise estimation of bias and quality of evidence [54].

Among patients of intermediate or poor IMDC risk, cabozantinib (multi-kinase inhibitor of MET, AXL, RET, and VEGFR2) demonstrated a significant benefit in PFS and ORR over sunitinib as the first-line treatment and is considered one of the standard first-line options [55]. However, the sample size of this phase II study was relatively limited and, when it came to subgroups and survival analysis, could affect the strength of the results. Combination strategies may overcome the resistance to immunotherapy through the immunomodulatory properties of VEGF-TKI inhibitors such as the increase in effector T-cell infiltration and decrease in inhibitory cell subpopulations, which could turn the cold tumors hot. In this setting, cabozantinib seems a promising partner for ICIs and is actually under investigation in clinical trials [56-58].

Several issues need to be addressed to define the better treatment strategy, particularly in patients with favorable IMDC risk, non-clear cell, and rare histological subtype. Lastly, further studies are expected to obtain a better selection of patient populations who are more likely to benefit from combination therapies of ICI with anti-CTLA-4 MoAbs or anti-angiogenic agents.

\section{Conclusions}

ICI studies challenge a paradigm shift in the management of RCC. To date, ICIs and targeted therapies are indicated for patients who have a specific risk score and not a specific tumor biomarker. This is consistent with the evidence that, to date, no reliable biomarker is able to predict which patients' subgroups will benefit from immunotherapy. Another relevant consideration is the definition of ideal time during treatment to administer an ICIs agent. In RCC, although cytoreductive nephrectomy is common, approximately $20-30 \%$ of metastasis-free patients will develop recurrent cancer after surgery, which highlights the need for an effective adjuvant therapy. Adjuvant immunotherapy is an attractive approach because it may enable the destruction of the microscopic tumor remaining after surgery, which reduces the relapse risk. According to recent reports, TKIs have not yet proven to be effective in the adjuvant setting, which suggests that a change paradigm of care like immunotherapy could have a role in the high-risk RCC adjuvant setting.

At last, emerging data with ICIs' agents and novel combination strategies represents a revolution for managing RCC, which results in an evolving scenario and is likely to further impact clinical decision-making. The establishment of valid predictors of treatment response to ICIs options is required to identify those patients who could benefit from these agents. Furthermore, a single biomarker for patient selection may not be feasible, given that immune responses are dynamic and evolve over time and, hence, will be necessary to integrate multiple components like PD-L1 expression, TILs, mutational load, and many other emergent biomarkers.

Author Contributions: All authors were involved in conceptualizing the manuscript. The Introduction and Conclusions sections were compiled by S.P., Anti-PD-1/PD-L1 single agent by V.E.P. Anti-PD-1/PD-L1 combined with other agents by E.P., Prognostic, and predictive biomarkers by D.L., L.A., M.M.M., L.D., and S.P. revised the manuscript. All authors approved submission of the manuscript. All authors have read and agreed to the published version of the manuscript.

Funding: This research received no external funding.

Conflicts of Interest: None of the authors have a conflict of interest to declare.

\section{Abbreviations}

$\begin{array}{ll}\text { AE } & \text { adverse event } \\ \text { CPS } & \text { combined positive score } \\ \text { CR } & \text { complete response } \\ \text { DCR } & \text { disease control rate } \\ \text { G } & \text { grade } \\ \text { HD } & \text { high dose }\end{array}$




$\begin{array}{ll}\text { HR } & \text { hazard ratio } \\ \text { ICI } & \text { immune-checkpoint inhibitors } \\ \text { IMDC } & \text { International Metastatic } \\ \text { RCC } & \text { Database Consortium } \\ \text { ITT } & \text { intention-to-treat } \\ \text { IV } & \text { intravenously } \\ \text { MoAb } & \text { monoclonal antibody } \\ \text { MSKCC } & \text { Motzer Score For Renal Cell Carcinoma } \\ \text { RCC } & \text { renal cell carcinoma } \\ \text { nccRCC } & \text { non-clear cell RCC } \\ \text { mRCC } & \text { metastatic RCC } \\ \text { ORR } & \text { objective response rate } \\ \text { OS } & \text { overall survival } \\ \text { PD } & \text { progressive disease } \\ \text { PD-L1 } & \text { programmed death-ligand 1 } \\ \text { PD-1 } & \text { programmed death 1 } \\ \text { PFS } & \text { progression-free survival } \\ \text { PR } & \text { partial response } \\ \text { RCC } & \text { renal cell carcinoma } \\ \text { RFS } & \text { recurrence-free survival } \\ \text { SD } & \text { stable disease } \\ \text { TMB } & \text { tumor mutational burden } \\ \text { TPS } & \text { tumor proportion score } \\ \text { TKI } & \text { tyrosine kinase inhibitor } \\ \text { tRCC } & \text { translocation RCC } \\ \text { VEGF } & \text { vascular endothelial growth factor } \\ \text { VEGF-R } & \text { vascular endothelial growth factor- receptor } \\ \text { WHO } & \text { World Health Organization } \\ & \end{array}$

\section{References}

1. Bray, F.; Ferlay, J.; Soerjomataram, I.; Siegel, R.L.; Torre, L.A.; Jemal, A. Global cancer statistics 2018 : GLOBOCAN estimates of incidence and mortality worldwide for 36 cancers in 185 countries. CA Cancer J. Clin. 2018, 68, 394-424. [CrossRef] [PubMed]

2. Rassy, E.; Flippot, R.; Albiges, L. Tyrosine kinase inhibitors and immunotherapy combinations in renal cell carcinoma. Ther. Adv. Med. Oncol. 2020, 12,1-13. [CrossRef] [PubMed]

3. Albiges, L.; Powles, T.; Staehler, M.; Bensalah, K.; Giles, R.H.; Hora, M.; Kuczyk, M.A.; Lam, T.B.; Ljungberg, B.; Marconi, L.; et al. Updated European Association of Urology Guidelines on Renal Cell Carcinoma: Immune Checkpoint Inhibition Is the New Backbone in First-line Treatment of Metastatic Clear-cell Renal Cell Carcinoma. Eur. Urol. 2019, 76, 151-156. [CrossRef] [PubMed]

4. Oliver, R.T.; Nethersell, A.B.; Bottomley, J.M. Unexplained spontaneous regression and alpha-interferon as treatment for metastatic renal carcinoma. Br. J. Urol. 1989, 63, 128-131. [CrossRef] [PubMed]

5. Coppin, C.; Porzsolt, F.; Awa, A.; Kumpf, J.; Coldman, A.; Wilt, T. Immunotherapy for advanced renal cell cancer. Cochrane Database Syst. Rev. 2005, 25, CD 001425.6.

6. Klapper, J.A.; Downey, S.G.; Smith, F.O.; Yang, J.C.; Hughes, M.S.; Kammula, U.S.; Sherry, R.M.; Royal, R.E.; Steinberg, S.M.; Rosenberg, S. High dose interleukin-2 for the treatment of metastatic renal cell carcinoma. Cancer 2008, 113, 293-301. [CrossRef]

7. Floros, T.; Tarhini, A.A. Anticancer cytokines: Biology and clinical effects of interferon-alpha2, interleukin (IL)-2, IL-15, IL-21, and IL-12. Semin. Oncol. 2015, 42, 539-548. [CrossRef]

8. Alsharedi, M.; Katz, H. Check point inhibitors a new era in renal cell carcinoma treatment. Med. Oncol. 2018, 4, 85. [CrossRef]

9. Parikh, M.; Bajwa, P. Immune Checkpoint Inhibitors in the Treatment of Renal Cell Carcinoma. Semin. Nephrol. 2020, 40, 76-85. [CrossRef] 
10. Garje, R.; An, J.; Greco, A.; Vaddepally, R.K.; Zakharia, Y. The Future of Immunotherapy-Based Combination Therapy in Metastatic Renal Cell Carcinoma. Cancers 2020, 7, 143. [CrossRef]

11. Topalian, S.L.; Hodi, F.S.; Brahmer, J.R.; Gettinger, S.N.; Smith, D.C.; McDermott, D.F.; Powderly, J.D.; Carvajal, R.D.; Sosman, J.A.; Atkins, M.B.; et al. Safety, Activity, and Immune Correlates of anti-PD-1 Antibody in Cancer. N. Engl. J. Med. 2012, 366, 2443-2454. [CrossRef]

12. Motzer, R.J.; Rini, B.I.; McDermott, D.F.; Redman, B.G.; Kuzel, T.M.; Harrison, M.R.; Vaishampayan, U.N.; Drabkin, H.A.; George, S.; Logan, T.F.; et al. Nivolumab for Metastatic Renal Cell Carcinoma: Results of a Randomized Phase II Trial. J. Clin. Oncol. 2015, 33, 1430-1437. [CrossRef] [PubMed]

13. Motzer, R.J.; Escudier, B.; David, F.; George, S.; Hammers, H.J.; Srinivas, S.; Tykodi, S.S.; Sosman, J.A.; Procopio, G.; Plimack, E.R.; et al. Nivolumab versus Everolimus in Advanced Renal-Cell Carcinoma. N. Engl. J. Med. 2015, 373, 1803-1813. [CrossRef] [PubMed]

14. Motzer, R.J.; Tykodi, S.S.; Escudier, B.; Oudard, S.; Hammers, H.J.; McDermott, D.F.; George, S.; Castellano, D.; Choueiri, T.K.; Alva, A.J.; et al. Final analysis of the CheckMate 025 trial comparing nivolumab (NIVO) versus everolimus (EVE) with $>5$ years of follow-up in patients with advanced renal cell carcinoma (aRCC). J. Clin. Oncol 2020, 38, 617. [CrossRef]

15. Ornstein, M.C.; Wood, L.S.; Hobbs, B.P.; Allman, K.D.; Martin, A.; Bevan, M.; Gilligan, T.D.; Garcia, J.A.; Rini, B.I. A phase II trial of intermittent nivolumab in patients with metastatic renal cell carcinoma (mRCC) who have received prior anti-angiogenic therapy. J. Immuno Ther. Cancer 2019, 7, 127. [CrossRef] [PubMed]

16. Grünwald, V.; Grüllich, C.; Ivanyi, P.; Wirth, M.; Staib, P.; Schostak, M.; Dargatz, P.; Müller, L.; Metz, M.; Bergmann, L.; et al. A randomized phase II trial comparing switch to nivolumab with TKI continuation after 12 weeks of TKI induction therapy in metastatic renal cell carcinoma patients (NIVOSWITCH). J. Clin. Oncol. 2020, 38, 6. [CrossRef]

17. Harshman, L.C.; Puligandla, M.; Allaf, M.E.; McDermott, D.F.; Drake, C.G.; Signoretti, S.; Cella, D.; Gupta, R.T.; Shuch, B.M.; Lara, P.; et al. PROSPER: Phase III randomized study comparing perioperative nivolumab versus observation in patients with renal cell carcinoma (RCC) undergoing nephrectomy (ECOG-ACRIN EA8143). J. Clin. Oncol. 2020, 38, 765. [CrossRef]

18. Au, L.; Litchfield, K.; Rowan, A.; Horswell, S.; Byrne, F.; Nicol, D.; Fotiadis, N.; Salgado, R.F.; Hazell, S.; Lopez, J.I.; et al. ADAPTeR: A phase II study of anti-PD1 (nivolumab) therapy as pre- and post-operative therapy in metastatic renal cell carcinoma. Ann. Oncol. 2019, 30, 356-402. [CrossRef]

19. Larkin, J.M.G.; Tykodi, S.S.; Donskov, F.; Lee, J.; Szczylik, C.; Malik, J.; Alekseev, B.Y.; Matveev, V.B.; Gafanov, R.A.; Tomczak, P.; et al. First line pembrolizumab (pembro) monotherapy in advanced clear cell carcinoma (ccRCC): Updated follow-up for Keynote-427 cohort A. Ann. Oncol. 2019, 30, 356-402. [CrossRef]

20. McDermott, D.F.; Lee, J.L.; Ziobro, M.; Gafanov, R.A.; Matveev, V.B.; Suárez, C.; Donskov, F.; Pouliot, F.; Alekseev, B.Y.; Wiechno, P.; et al. First-line pembrolizumab (pembro) monotherapy for advanced non-clear cell renal cell carcinoma (nccRCC): Results from KEYNOTE-427 cohort B. J. Clin. Oncol. 2019, 37, 4569. [CrossRef]

21. Choueiri, T.; Quinn, D.I.; Zhang, T.; Gurney, H.; Doshi, G.K.; Cobb, P.W.; Lee, F.P.J.; Park, S.H.; Semenov, A.; Chang, W.Y.; et al. KEYNOTE-564: A phase 3, randomized, double blind, trial of pembrolizumab in the adjuvant treatment of renal cell carcinoma. J. Clin. Oncol. 2018, 36, 4599. [CrossRef]

22. Uzzo, R.; Bex, A.; Rini, B.I.; Albiges, L.; Suarez, C.; Donaldson, F.; Asakawa, T.; Schiff, C.; Pal, S.K. A phase III study of atezolizumab (atezo) vs. placebo as adjuvant therapy in renal cell carcinoma (RCC) patients (pts) at high risk of recurrence following resection (IMmotion010). J. Clin. Oncol. 2017, 35, 4598. [CrossRef]

23. Vaishampayan, U.; Schoffski, P.; Ravaud, A.; Borel, C.; Peguero, J.; Chaves, J.; Morris, J.C.; Kotecki, N.; Smakal, M.; Zhou, D.; et al. Avelumab monotherapy as first-line or second-line treatment in patients with metastatic renal cell carcinoma: Phase Ib results from the JAVELIN 2019 Solid Tumor Trial. J. Immunother. Cancer 2019, 7, 275. [CrossRef] [PubMed]

24. Motzer, R.J.; Tannir, N.M.; McDermott, D.F.; Arén Frontera, O.; Melichar, B.; Choueiri, T.K.; Plimack, E.R.; Barthélémy, P.; Porta, C.; George, S.; et al. Nivolumab plus Ipilimumab versus Sunitinib in Advanced Renal-Cell Carcinoma. N. Engl. J. Med. 2018, 378, 1277-1290. [CrossRef]

25. Motzer, R.J.; Rini, B.I.; McDermott, D.F.; Arén Frontera, O.; Hammers, H.J.; Carducci, M.A.; Salman, P.; Escudier, B.; Beuselinck, B.; Amin, A.; et al. Nivolumab plus ipilimumab versus sunitinib in first-line treatment for advanced renal cell carcinoma: Extended follow-up of efficacy and safety results from a randomised, controlled, phase 3 trial. Lancet Oncol. 2019, 20, 1370-1385. [CrossRef] 
26. Rini, B.I.; Plimack, E.R.; Stus, V.; Gafanov, R.; Hawkins, R.; Nosov, D.; Pouliot, F.; Alekseev, B.; Soulières, D.; Melichar, B.; et al. Pembrolizumab plus Axitinib versus Sunitinib for Advanced Renal-Cell Carcinoma. N. Engl. J. Med. 2019, 380, 1116-1127. [CrossRef]

27. Rini, B.I.; Plimack, E.R.; Stus, V.; Gafanov, R.; Hawkins, R.; Nosov, D.; Pouliot, F.; Soulières, D.; Melichar, B.; Vynnychenko, I.; et al. Pembrolizumab (pembro) plus axitinib (axi) versus sunitinib as first-line therapy for metastatic renal cell carcinoma (mRCC): Outcomes in the combined IMDC intermediate/poor risk and sarcomatoid subgroups of the phase 3 KEYNOTE-426 study. J. Clin. Oncol. 2019, 37, 4500. [CrossRef]

28. Motzer, R.J.; Penkov, K.; Haanen, J.; Rini, B.; Albiges, L.; Campbell, M.T.; Venugopal, B.; Kollmannsberger, C.; Negrier, S.; Uemura, M.; et al. Avelumab plus Axitinib versus Sunitinib for Advanced Renal-Cell Carcinoma. N. Engl. J. Med. 2019, 380, 1103-1115. [CrossRef]

29. Motzer, R.J.; Powles, T.; Atkins, M.B.; Escudier, B.; McDermott, D.F.; Suarez, C.; Bracarda, S.; Stadler, W.M.; Donskov, F.; Lee, J.; et al. IMmotion151: A Randomized Phase III Study of Atezolizumab Plus Bevacizumab vs. Sunitinib in Untreated Metastatic Renal Cell Carcinoma (mRCC). J. Clin. Oncol. 2018, 36, 578. [CrossRef]

30. Koshkin, V.S.; Barata, P.C.; Zhang, T.; George, D.J.; Atkins, M.B.; Kelly, W.J.; Vogelzang, N.J.; Pal, S.K.; Hsu, J.; Appleman, L.J.; et al. Clinical activity of nivolumab in patients with non-clear cell renal cell carcinoma. J. Immunother. Cancer 2018, 6, 9. [CrossRef]

31. McKay, R.R.; Bossé, D.; Xie, W.; Wankowicz, S.A.M.; Flaifel, A.; Brandao, R.; Lalani, A.A.; Martini, D.J.; Wei, X.X.; Braun, D.A.; et al. The Clinical Activity of PD-1/PD-L1 Inhibitors in Metastatic Non-Clear Cell Renal Cell Carcinoma. Cancer Immunol. Res. 2018, 6, 758-765. [CrossRef] [PubMed]

32. Chahoud, J.; Msaouel, P.; Campbell, M.T.; Bathala, T.; Xiao, L.; Gao, J.; Zurita, A.J.; Shah, A.Y.; Jonasch, E.; Sharma, P.; et al. Nivolumab for the Treatment of Patients with Metastatic Non-Clear Cell Renal Cell Carcinoma (nccRCC): A Single-Institutional Experience and Literature Meta-Analysis. Oncologist 2019, 25, 252-258. [CrossRef] [PubMed]

33. Suárez, C.; Lee, J.; Ziobro, M.; Gafanov, R.A.; Matveev, V.B.; Donskov, F.; Pouliot, F.; Alekseev, B.Y.; Wiechno, P.J.; Tomczak, P.; et al. First-line pembrolizumab (pembro) monotherapy for advanced non-clear cell renal cell carcinoma (nccRCC): Updated follow-up for KEYNOTE-427 cohort B. Ann. Oncol. 2019, 30, 356-402. [CrossRef]

34. Vogelzang, N.J.; McFarlane, J.J.; Kochenderfer, M.D.; Molina, A.M.; Arrowsmith, E.; Bauer, T.M.; Hauke, R.J.; Jain, R.; Somer, B.G.; Lam, E.T.; et al. Efficacy and safety of nivolumab in patients with non-clear cell renal cell carcinoma (RCC): Results from the phase IIIb/IV CheckMate 374 study. J. Clin. Oncol. 2019, 37, 7. [CrossRef]

35. McKay, R.R.; McGregor, B.A.; Gray, K.; Steinharter, J.A.; Walsh, M.K.; Braun, D.A.; Flaifel, A.; VanAllen, E.; Wei, X.X.; Signoretti, S.; et al. Results of a phase II study of atezolizumab and bevacizumab in non-clear cell renal cell carcinoma (nccRCC) and clear cell renal cell carcinoma with sarcomatoid differentiation (sccRCC). J. Clin. Oncol. 2019, 37, 7. [CrossRef]

36. Suarez, R.C.; Larkin, J.M.G.; Patel, P.; Valderrama, B.P.; Rodriguez-Vida, A.; Glen, H.; Thistlethwaite, F.; Ralph, C.; Srinivasan, G.; Vidal, M.J.J.M.; et al. Overall survival results of durvalumab and savolitinib in metastatic papillary renal cancer. JCO 2020, 38, 619. [CrossRef]

37. Inamura, K. Translocation Renal Cell Carcinoma: An Update on Clinicopathological and Molecular Features. Cancers 2017, 9, 111. [CrossRef]

38. Boilève, A.; Carlo, M.I.; Barthélémy, P.; Oudard, S.; Borchiellini, D.; Voss, M.H.; George, S.; Chevreau, C.; Landman-Parker, J.; Tabone, M.-D.; et al. Immune checkpoint inhibitors in MITF family translocation renal cell carcinomas and genetic correlates of exceptional responders. J. Immunother. Cancer 2018, 6, 159.

39. Choueiri, T.K.; Albiges, L.; Haanen, J.B.A.G.; Larkin, J.M.G.; Uemura, M.; Pal, S.K.; Gravis, G.; Campbell, M.T.; Penkov, K.; Lee, J.; et al. Biomarker analyses from JAVELIN Renal 101: Avelumab + axitinib (A + Ax) versus sunitinib (S) in advanced renal cell carcinoma (aRCC). J. Clin. Oncol. 2019, 37, 101. [CrossRef]

40. Thompson, R.H.; Kuntz, S.M.; Leibovich, B.C.; Dong, H.; Lohse, C.M.; Webster, W.S.; Sengupta, S.; Frank, I.; Parker, A.S.; Zincke, H.; et al. Tumor B7-H1 is associated with poor prognosis in renal cell carcinoma patients with long-term follow-up. Cancer Res. 2006, 66, 3381-3385. [CrossRef]

41. Miao, D.; Margolis, C.A.; Gao, W.; Voss, M.H.; Li, W.; Martini, D.J.; Norton, C.; Bossé, D.; Wankowicz, S.M.; Cullen, D.; et al. Genomic correlates of response to immune checkpoint therapies in clear cell renal cell carcinoma. Science 2018, 59, 801-806. [CrossRef] [PubMed] 
42. Braun, D.A.; Ishii, Y.; Walsh, A.M.; Van Allen, E.M.; Wu, C.J.; Shukla, S.A.; Choueiri, T.K. Clinical Validation of PBRM1 Alterations as a Marker of Immune Checkpoint Inhibitor Response in Renal Cell Carcinoma. JAMA Oncol. 2019, 5, 1631-1633. [CrossRef] [PubMed]

43. Voss, M.H.; Novik, J.B.; Hellmann, M.D.; Ball, M.; Hakimi, A.A.; Miao, D.; Margolis, C.; Horak, C.; Wind-Rotolo, M.; De Velasco, G.; et al. Correlation of degree of tumor immune infiltration and insertion-and-deletion (indel) burden with outcome on programmed death 1 (PD1) therapy in advanced renal cell cancer (RCC). J. Clin. Oncol. 2018, 36, 4518. [CrossRef]

44. McDermott, D.F.; Huseni, M.A.; Atkins, M.B.; Motzer, R.J.; Rini, B.I.; Escudier, B.; Fong, L.; Joseph, R.W.; Pal, S.K.; Reeves, J.A.; et al. Clinical activity and molecular correlates of response to atezolizumab alone or in combination with bevacizumab versus sunitinib in renal cell carcinoma. Nat. Med. 2018, 24, 749-757. [CrossRef] [PubMed]

45. Madore, J.; Vilain, R.E.; Menzies, A.M.; Kakavand, H.; Wilmott, J.S.; Hyman, J.; Yearley, J.H.; Kefford, R.F.; Thompson, J.F.; Long, G.V.; et al. PD-L1 expression in melanoma shows marked heterogeneity within and between patients: Implications for anti-PD-1/PD-L1 clinical trials. Pigment Cell Melanoma Res. 2015, 28, 245-253. [CrossRef] [PubMed]

46. McLaughlin, J.; Han, G.; Schalper, K.A.; Carvajal-Hausdorf, D.; Pelekanou, V.; Rehman, J.; Velcheti, V.; Herbst, R.; LoRusso, P.; Rimm, D.L. Quantitative Assessment of the Heterogeneity of PD-L1 Expression in Non-Small-Cell Lung Cancer. JAMA Oncol. 2016, 2, 46-54. [CrossRef]

47. Rimm, D.L.; Han, G.; Taube, J.M.; Yi, E.S.; Bridge, J.A.; Flieder, D.B.; Homer, R.; West, W.W.; $\mathrm{Wu}, \mathrm{H} . ;$ Roden, A.C.; et al. A prospective, multi-institutional, pathologist-based assessment of 4 immunohistochemistry assays for PD-L1 expression in non-small cell lung cancer. JAMA Oncol. 2017, 3, 1051-1058. [CrossRef]

48. Choueiri, T.K.; Fishman, M.N.; Escudier, B.; McDermott, D.F.; Drake, C.G.; Kluger, H.; Stadler, W.M.; Perez-Gracia, J.L.; McNeel, D.G.; Curti, B.; et al. Immunomodulatory Activity of Nivolumab in Metastatic Renal Cell Carcinoma. Clin. Cancer Res. 2016, 22, 5461-5471. [CrossRef]

49. Rizvi, N.A.; Hellmann, M.D.; Snyder, A.; Kvistborg, P.; Makarov, V.; Havel, J.J.; Lee, W.; Yuan, J.; Wong, P.; Ho, T.S.; et al. Mutational landscape determines sensitivity to PD-1 blockade in non-small cell lung cancer. Science 2015, 348, 124-128. [CrossRef]

50. Le, D.T.; Uram, J.N.; Wang, H.; Bartlett, B.R.; Kemberling, H.; Eyring, A.D.; Skora, A.D.; Luber, B.S.; Azad, N.S.; Laheru, D.; et al. PD-1 blockade in tumors with mismatch-repair deficiency. N. Engl. J. Med. 2015, 372, 2509-2520. [CrossRef]

51. Creighton, C.J.; Morgan, M.; Gunaratne, P.H.; Wheeler, D.A.; Gibbs, R.A.; Robertson, A.G.; Chu, A.; Beroukhim, R.; Cibulskis, K.; Signoretti, S.; et al. Cancer Genome Atlas Research Network: Comprehensive molecular characterization of clear cell renal cell carcinoma. Nature 2013, 499, 43-49.

52. Turajlic, S.; Litchfield, K.; Xu, H.; Rosenthal, R.; McGranahan, N.; Reading, J.L.; Wong, Y.N.S.; Rowan, A.; Kanu, N.; Bakir, M.A.; et al. Insertion-and-deletion-derived tumour-specific neoantigens and the immunogenic phenotype: A pan-cancer analysis. Lancet Oncol. 2017, 18, 1009-1021. [CrossRef]

53. Choueiri, T.K.; Fay, A.P.; Gray, K.P.; Callea, M.; Ho, T.H.; Albiges, L.; Bellmunt, J.; Song, J.; Carvo, I.; Lampron, M.; et al. PD-L1 expression in nonclear-cell renal cell carcinoma. Ann. Oncol. 2014, 25, 2178-2184. [CrossRef]

54. Peinemann, F.; Unverzagt, S.; Hadjinicolaou, A.V.; Moldenhauer, I. Immunotherapy for metastatic renal cell carcinoma: A systematic review. J. Evid. Based Med. 2019, 12, 253-262. [CrossRef] [PubMed]

55. Choueiri, T.K.; Halabi, S.; Sanford, B.L.; Hahn, O.; Michaelson, M.D.; Walsh, M.K.; Feldman, D.R.; Olencki, T.; Picus, J.; Small, E.J.; et al. Cabozantinib Versus Sunitinib as Initial Targeted Therapy for Patients with Metastatic Renal Cell Carcinoma of Poor or Intermediate Risk: The Alliance A031203 CABOSUN Trial. J. Clin. Oncol. 2017, 35, 591-597. [CrossRef] [PubMed]

56. Bergerot, P.; Lamb, P.; Wang, E.; Pal, S.K. Cabozantinib in Combination with Immunotherapy for Advanced Renal Cell Carcinoma and Urothelial Carcinoma: Rationale and Clinical Evidence. Mol. Cancer Ther. 2019, 18, 2185-2193. [CrossRef] 
57. Rini, B.I.; Battle, D.; Figlin, R.A.; George, D.J.; Hammers, H.; Hutson, T.; Jonasch, E.; Joseph, R.W.; McDermott, D.F.; Motzer, R.J.; et al. The society for immunotherapy of cancer consensus statement on immunotherapy for the treatment of advanced renal cell carcinoma (RCC). J. Immunother. Cancer 2019, 7, 354. [CrossRef]

58. Terme, M.; Colussi, O.; Marcheteau, E.; Tanchot, C.; Tartour, E.; Taieb, J. Modulation of immunity by antiangiogenic molecules in cancer. Clin. Dev. Immunol. 2012, 2012, 492920. [CrossRef] 